Review Article

\title{
A Review and Comparative Study of Existing Shrinkage Prediction Models for Portland and Non-Portland Cementitious Materials
}

\author{
Hailong Ye and Aleksandra Radlińska \\ Department of Civil and Environmental Engineering, The Pennsylvania State University, 3127 Research Drive, \\ State College, PA 16801, USA \\ Correspondence should be addressed to Hailong Ye; huy131@psu.edu
}

Received 26 November 2015; Accepted 11 February 2016

Academic Editor: Charles C. Sorrell

Copyright ( 2016 H. Ye and A. Radlińska. This is an open access article distributed under the Creative Commons Attribution License, which permits unrestricted use, distribution, and reproduction in any medium, provided the original work is properly cited.

This paper reviews shrinkage prediction models for cementitious materials and presents analysis of selected published data utilizing the aforementioned models. The main objective of this review is to revisit and reexamine the primary shrinkage mechanisms, that is, capillary pressure theory, Gibbs-Bangham shrinkage, and withdrawal of disjoining pressure in Portland and non-Portland cement. In particular, the theoretical basis for current shrinkage models is elaborated on and its soundness and applicability to explain the published experimental data are discussed. Additionally, a specific comparison was made among high water-to-cement (w/c) ratio ordinary Portland cement (OPC), low w/c OPC, and alkaline activated slag.

\section{Introduction}

Volumetric stability is an important engineering property of any cementitious material, as it can significantly affect the long-term durability and serviceability of concrete structures [1]. At early ages, when volume reduction (i.e., shrinkage) occurs under restrained conditions, concrete structures frequently experience premature cracking. The drying shrinkage and autogenous shrinkage correspond to the reduction of volume due to external and internal moisture loss, respectively. Autogenous shrinkage is associated with loss of internal water through hydration (self-desiccation), while drying shrinkage is associated with loss of water through evaporation [2-4]. Since the physical origin of these two types of shrinkage is similar, the principle focus of shrinkage research is correlation between shrinkage deformation and shrinkage driving forces. The shrinkage driving force is triggered by the dryinginduced changes of water content and status (e.g., water in capillary tension or in adsorbed films) at various length scales. As such, before either drying or autogenous shrinkage can be predicted accurately, the underlying shrinkage driving force needs to be better understood. Despite the extensive investigation by previous researchers, the shrinkage mechanism or driving force behind shrinkage has not been well explained [5]. The focus of the first part of this paper is a thorough review of the theoretical basis of various shrinkage mechanisms to provide relevant evidence and justifications for their applicability to cementitious materials. The second part focuses on comparison of shrinkage mechanisms in ordinary Portland cement and alkali-activated slag binders.

The shrinkage performance and relevant mechanisms of porous cementitious systems are intimately related to their microstructure, including pore size distribution, surface area, morphology of hydrate solids, and pore solution properties [6-9]. Therefore, it is not surprising that the shrinkage phenomenon (regardless of drying or autogenous origin) has been reported to vary considerably for different types of cementitious materials [6,10-14]. For instance, while the shrinkage value of ordinary Portland cement (OPC) is dependent on water-to-cement $(\mathrm{w} / \mathrm{c})$ ratio [15], that response will be altered for OPC blended with supplementary cementitious materials (SCM) such as slag and fly ash [10]. On the other hand, OPC-free alkaline activated slag (AAS) or fly ash (geopolymer) is characterized by yet another shrinkage 
response $[6,11,14,16,17]$. However, it is still unclear why the shrinkage performance can be dramatically different for various types of cementitious materials (e.g., high w/c OPC, low w/c OPC, AAS). As such, the potentially intrinsic differences that control the shrinkage characteristics among various cementitious systems are discussed in this paper.

The aforementioned alkaline activated slag (AAS) is an emerging binder prepared by combining blast-furnace slag, a byproduct of steel production, and an alkaline solution (e.g., sodium hydroxide and/or sodium silicate). Alkali-activated slag has become a promising alternative to conventional OPC. It is because AAS can not only have superior performance and durability over OPC but also have the potential to have a lower environmental impact, since it reuses industrial byproducts and as such reduces waste material deposition and does not require additional energy for material production [18]. However, this new binder suffers from several problems as a building material, including large volumetric instability and microcracking $[6,12,19,20]$. The scientific reasoning behind the considerable shrinkage of AAS has not been exclusively reported. Another goal of this research is to explore the potential reasons that are responsible for the unique shrinkage performance of AAS. Finally, this review also attempts to highlight some drawbacks in the present shrinkage models and to provide some recommendations for further shrinkage research.

\section{Motivation for This Study}

The primary motivation for this study is to provide understanding of the origin of large shrinkage deformations in alkali-activated systems. According to extensive investigations regarding drying shrinkage performance of AAS pastes and mortars at various drying conditions (e.g., different drying relative humidity and drying procedures), it is recognized that AAS exhibits a viscoelastic/plastic deformation response upon drying $[12,14]$. As shown in Figure 1, AAS loses more moisture and exhibits larger shrinkage than OPC. Most of the existing shrinkage prediction models have difficulty explaining the scientific reasons behind the large shrinkage of AAS. This motivates the authors to reconsider the likely intrinsic difference between OPC and other non-OPC cementitious systems. This difference can originate from either a difference in the nature and magnitude of shrinkage driving forces or mechanical responses among various cementitious materials. Therefore, the theoretical basis for shrinkage driving forces is reviewed in this paper first, followed by its applicability to shrinkage prediction of various cementitious materials.

\section{Shrinkage Mechanisms and Prediction Models}

Several shrinkage prediction models have been extensively documented in the literature over the last decades. These models can be roughly classified into two groups: empirical models, such as the fib Model Code for Concrete Structures 2010, and mechanism-based theoretical models, for example, the thermodynamic model proposed by Powers [23].
Empirical models are mainly established through statistical regression analysis of field-collected or experimentally measured data [24]. The shrinkage mechanisms involved in these empirical models are inconspicuous in a physical sense (e.g., the shrinkage prediction model in the fib Model Code is primarily based on concrete compressive strength) and hence are not discussed in the present paper.

In case of mechanism-based models, Powers, in 1968, was the first one to provide a documented description of the shrinkage mechanisms and physical modeling from a viewpoint of thermodynamics [23]. Subsequently, shrinkage mechanism of cementitious materials was extensively researched and several physical models were established. Generally, four primary drying shrinkage mechanisms were suggested by previous researchers, namely, (1) capillary pressure theory [25-28], (2) Gibbs-Bangham shrinkage (variation in solid surface tension) [8, 28-30], (3) withdrawal of disjoining pressure [30-35], and (4) movement of interlayer water from calcium-silicate-hydrate $(\mathrm{C}-\mathrm{S}-\mathrm{H})$ gel $[36,37]$. Despite the extensive research performed, no agreement has been achieved so far on the dominant shrinkage mechanism. It was previously acknowledged that different shrinkage mechanisms may govern at different relative humidity $(\mathrm{RH})$ ranges and over various sizes of pores [38]. However, this ambiguous argument still cannot provide a clear judgment on how the shrinkage mechanisms operate in cementitious materials exactly or how the shrinkage can be correlated with microstructural characteristics. As such, this paper attempts to illuminate the factors controlling the shrinkage characteristics of Portland and non-Portland cementitious systems.

\subsection{Capillary Pressure}

3.1.1. Theoretical Basis for Capillary Pressure. From a thermodynamic viewpoint, vapor-liquid equilibrium is a condition where the rate of evaporation is equal to the rate of condensation on a molecular level, such that there is no net vaporliquid interconversion. Thus, no evaporation occurs at $100 \%$ $\mathrm{RH}$, since the vapor pressure is equal to the saturated vapor pressure. As RH (vapor pressure) decreases, the equilibrium condition is violated and evaporation takes place. However, in a porous medium such as cement-based materials, the equilibrium can be restored due to the formation of menisci in the pores. In other words, it is possible to reach equilibrium when the vapor pressure over a meniscus is lower than the saturated vapor pressure for cementitious materials. The difference between the gas pressure above the meniscus and pressure inside the liquid is called capillary pressure, as expressed in Young-Laplace equation $[39,40]$ in the following:

$$
P_{c}=P_{g}-P_{l}=-\frac{2 \gamma \cos \theta}{r_{c}-t}
$$

where $P_{c}$ is the capillary pressure $[\mathrm{Pa}], P_{g}$ is the gas pressure $[\mathrm{Pa}], P_{l}$ is the liquid pressure $[\mathrm{Pa}], r_{c}$ is the capillary radius at the position of meniscus (also named as the Kelvin radius) $[\mathrm{m}], \gamma$ is the surface tension between pore water and vapor 


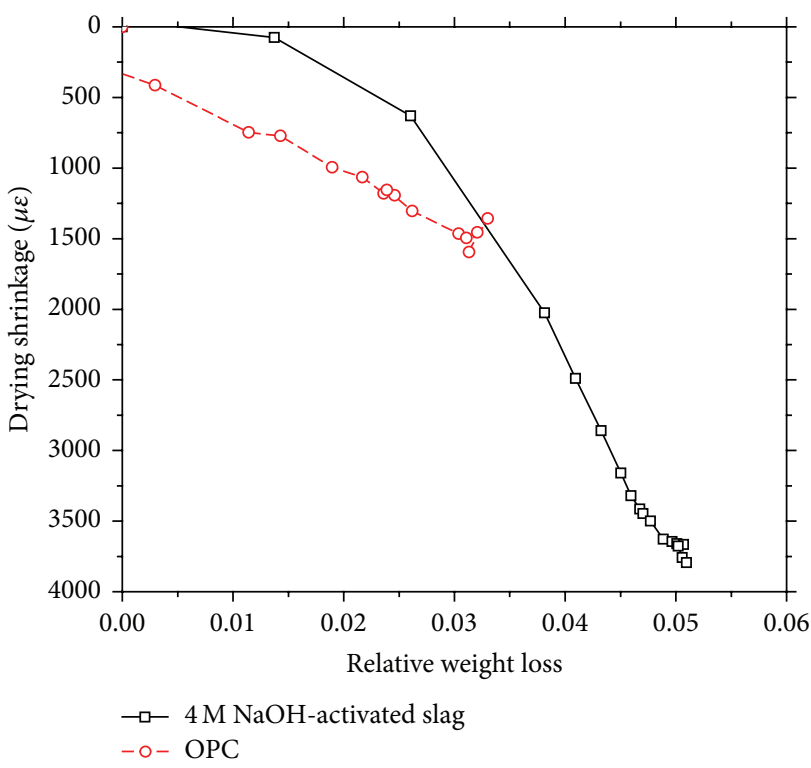

(a)

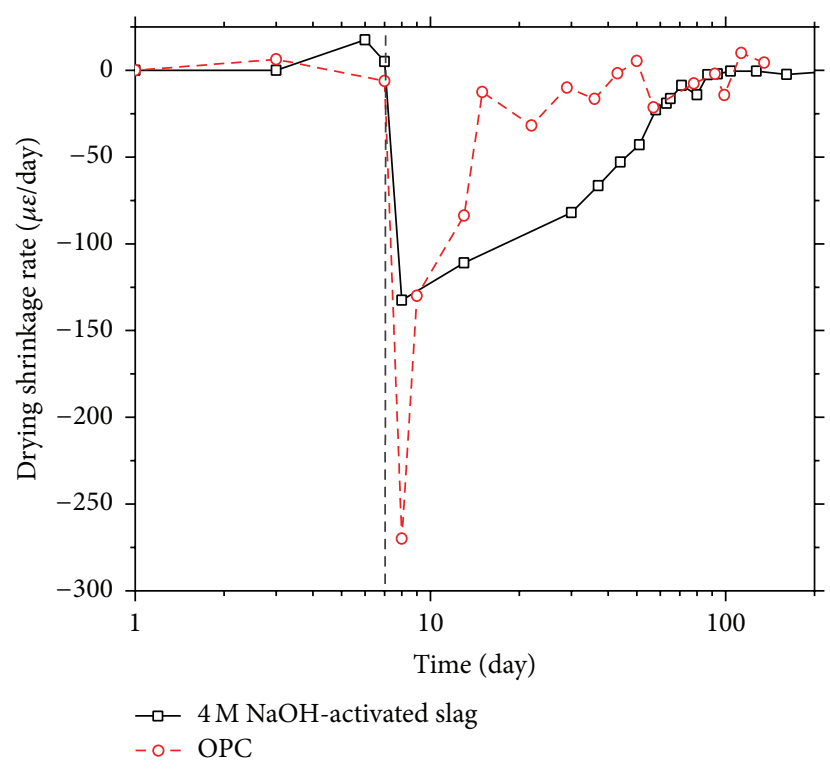

(b)

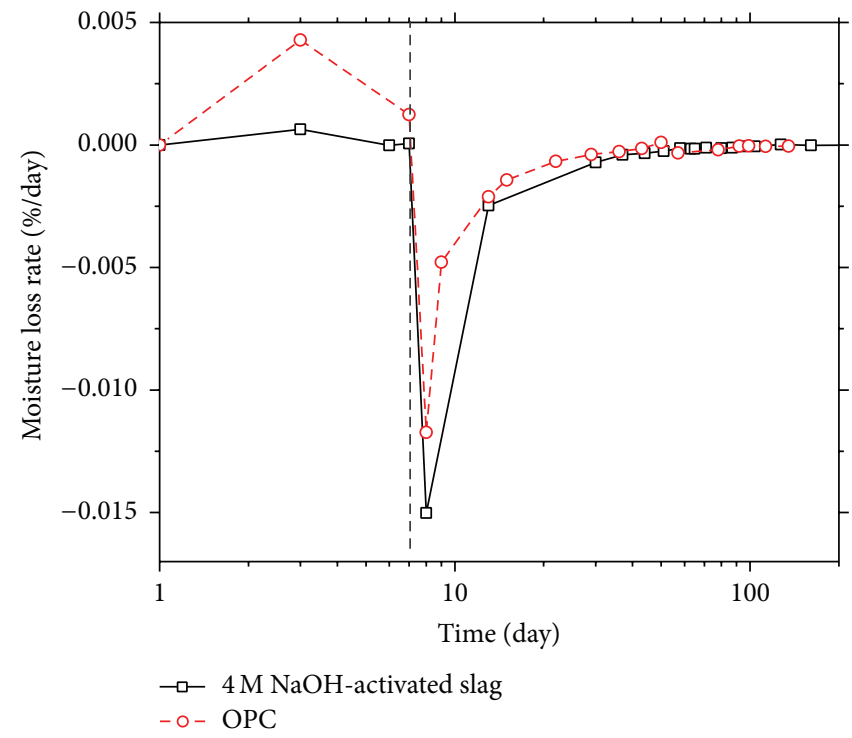

(c)

FIGURE 1: (a) The correlation between drying shrinkage strain and relative weight loss present in AAS and OPC systems; (b) the timedependent change of drying shrinkage rate in AAS and OPC systems; (c) the time-dependent change of moisture loss rate based on data from author's previous publication [14]; the dashed lines in (b) and (c) indicate the time when drying was initiated, that is, 7 days.

$[\mathrm{N} / \mathrm{m}], \theta$ is the contact angle denoting the hydrophilicity of the pore wall $\left[{ }^{\circ}\right]$, and $t$ is the thickness of an adsorbed layer $[\mathrm{m}]$, which is a function of $\mathrm{RH}[29,41]$.

Another important physical law is Kelvin's equation, which establishes the correlation between capillary pressure and $\mathrm{RH}$, as shown in the following [42]:

$$
P_{c}=\rho_{l} R M^{-1} T \ln \frac{\mathrm{RH}}{x_{w}},
$$

where $\rho_{l}$ is the density of liquid $\left[\mathrm{kg} / \mathrm{m}^{3}\right], M$ is the molar mass of liquid $[\mathrm{kg} / \mathrm{mol}], R=8.314[\mathrm{~J} /(\mathrm{mol} \cdot \mathrm{K})]$ is the universal gas constant, $T$ is the temperature $[\mathrm{K}]$, and $x_{w}$ accounts for the presence of ions in the pore solution based on Raoult's law, for example. Most existing capillary pressure-based models begin with these two fundamental equations (see (1) and (2)) (abbreviated as Kelvin-Laplace equation) to establish the mechanical and thermodynamic equilibrium between liquid and gas.

Based on Kelvin-Laplace equation (see (1) and (2)), it can be seen that the determination of Kelvin radius is primarily based on the $\mathrm{RH}$ and pore solution properties, irrespective of the pore size. In other words, the menisci in all the pores at a drying surface are equal under equilibrium, as shown in Figure 2. Considering that various size pores are interconnected, the potential difference in menisci 

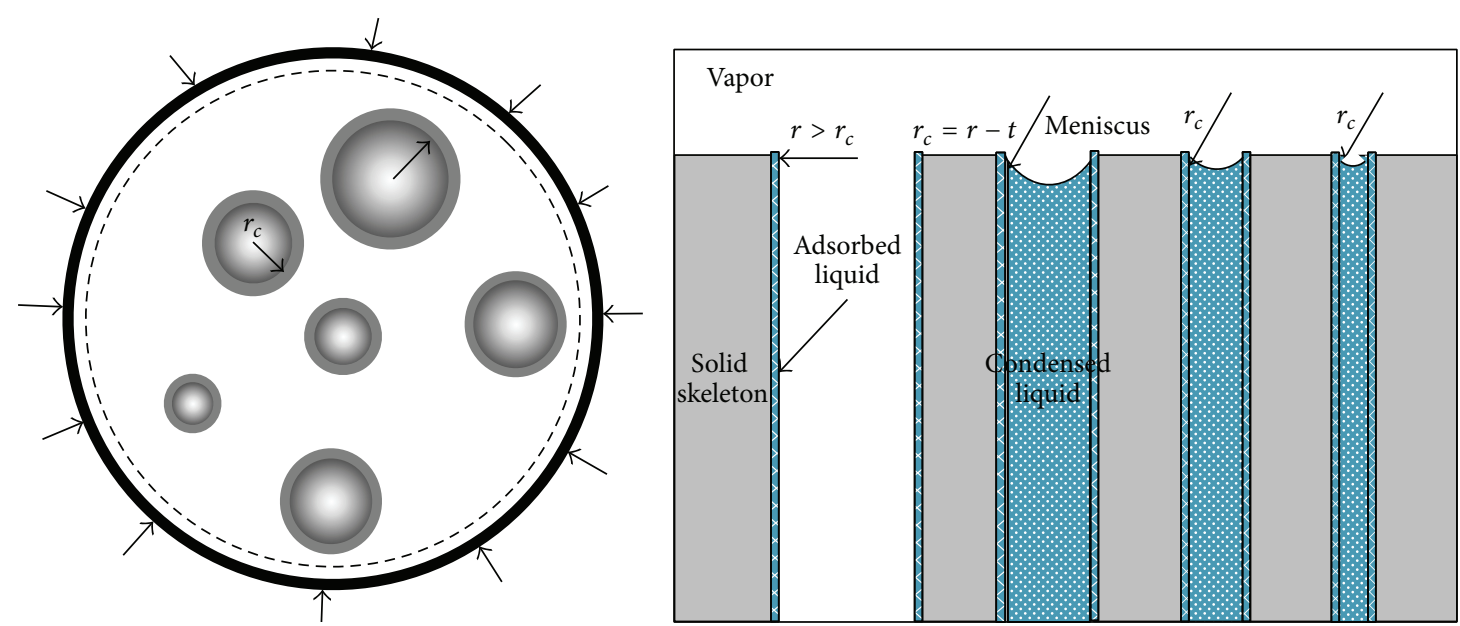

FIGURE 2: Schematic illustration of drying process with different pore sizes, the formation of meniscus and generation of capillary pressure.

radius (if it exists before reaching equilibrium) would result in a gradient of capillary pressure, which further induces water movement until equilibrium is restored. As RH keeps decreasing, the radius of the menisci decreases in all pores, toward reaching a new Kelvin radius. As the Kelvin radius becomes smaller than the radius of the pores (neglecting the adsorbed layers), the water in these pores begins to drain, since the meniscus has reached the limit and cannot further decrease in size. In addition, the gradient in meniscus radius (or capillary pressure) drives liquid movement from larger pores to smaller pores [43]. As such, larger pores always empty first. Therefore, when equilibrated at certain $\mathrm{RH}$, all surface pores whose radii are smaller than the Kelvin radius are completely filled with water, whereas larger surface pores are dried and only contain a layer of adsorbed water $[22,44]$ (see Figure 2).

However, in realistic cases, the amount of water that exists in a particular cementitious system at certain $\mathrm{RH}$ is dependent on not only the pore size distribution but also the drying history. This is observed as the strong hysteresis in water vapor adsorption/desorption isotherms in cementitious materials due to the effects of tortuosity and connectivity of pore structure (also named "ink-bottle" effect) [45]. It emphasizes the importance of considering the tortuosity and connectivity of pore structure in establishing shrinkage prediction models for cementitious materials, since most existing capillary pressure-based models assume the pores to have cylindrical or circular shapes. A recent study [46] regarding the volumetric changes in porous materials due to moisture variation demonstrated that the model with cylindrical pores fails to explain the pronounced hysteresis (i.e., volumetric change versus $\mathrm{RH}$ ) for cementitious materials. One possible explanation for the discrepancies is due to oversimplification in the microstructure description of the pore size distribution.

It should be noted that the liquid in capillary pores is under hydrostatic tensile stress and can exert force to pull adjacent walls closer. Most of existing capillary pressurebased models assume the capillary pores to be cylindrical, isolated, and randomly distributed throughout the volume of the material. In simplified models, the material is further treated as elastic and isotropic. The linear shrinkage strain resulting from the internal capillary pressure can be calculated using

$$
\varepsilon_{\text {cap }}=\frac{1}{3}\left(\frac{1}{K}-\frac{1}{K_{s}}\right) \int_{0}^{r_{\max }}[P(r) \cdot f(r)] d r,
$$

where $\varepsilon_{\text {cap }}$ is the capillary pressure-driven linear shrinkage strain, $K$ is the bulk modulus of the whole porous body [Pa], $K_{s}$ is the bulk modulus of the solid material [Pa], $P(r)$ is the capillary stress in the pores with a radius of $r[\mathrm{~Pa}]$, and $f(r)$ is the probability density function of volume of capillary pores with radius $r$ [unitless] (i.e., volume of pores with radii of $r$ /total pore volume). According to Kelvin-Laplace equation, for a given interior $\mathrm{RH}$, a constant capillary stress is generated in the capillary pores (i.e., $P(r)=P_{c}$ ), regardless of pore radius. Meanwhile, it can be shown that merely the radii larger than the Kelvin radius $r_{c}$ are able to from menisci and generate capillary pressure. Thus, (3) can be rewritten as

$$
\varepsilon_{\text {cap }}=-\int_{0}^{r_{c}} f(r) d r \cdot \frac{1}{3}\left(\frac{1}{K}-\frac{1}{K_{s}}\right) P_{c} .
$$

According to (4), capillary pressure-induced shrinkage is dependent on the pore size distribution of the cementitious material, which is affected by, for example, w/c ratio, addition of SCM, and varies with age and curing conditions. As shown in Figure 3(b), assuming that $g(r)$ represents the cumulative distribution function up to pore radius $r$, it satisfies

$$
\begin{aligned}
\frac{\partial g(r)}{\partial r} & =f(r) \\
\int_{0}^{r_{c}} f(r) d r & =\int_{0}^{r_{c}}\left(\frac{\partial g(r)}{\partial r}\right) d r=g\left(r_{c}\right) .
\end{aligned}
$$

It can be seen that the term in (6) is approximately equal to the degree of saturation $S_{w}$ (i.e., total volume of saturated pores/total pore volume), when the amount of adsorbed 


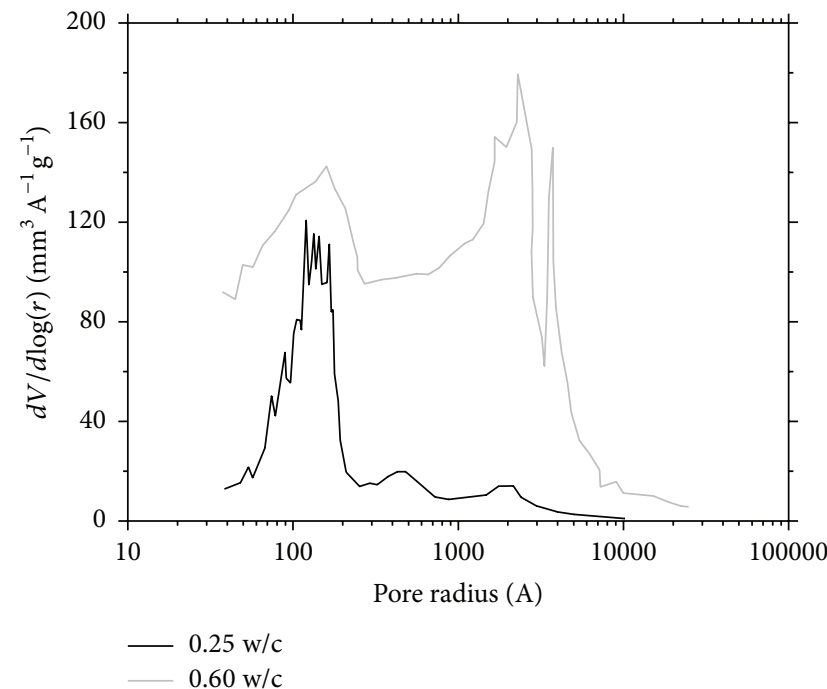

(a)

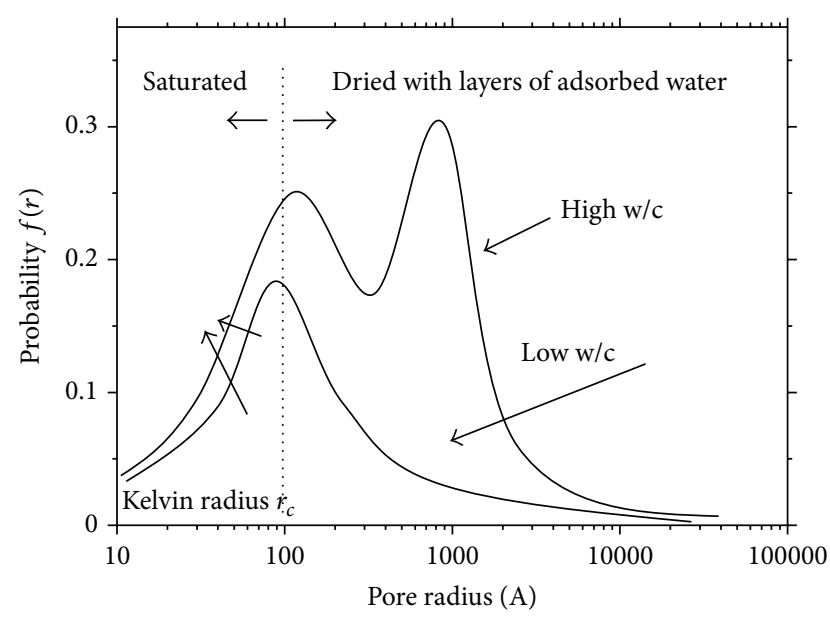

(b)

FIgURE 3: (a) Pore size distribution for OPC with w/c $=0.6$ and w/c $=0.25$ (data adopted from Figure 10(a) in [15], where the averaged data points are selected to represent the approximate pore size distribution profiles). (b) Comparison of pore size distribution of typical high w/c OPC and low w/c OPC and their corresponding capillary water states.

water is negligible as compared with that of capillary water. Thus, (4) can be further rewritten as

$$
\varepsilon_{\text {cap }}=-g\left(r_{c}\right) \cdot \frac{1}{3}\left(\frac{1}{K}-\frac{1}{K_{s}}\right) P_{c} \approx-\frac{S_{w}}{3}\left(\frac{1}{K}-\frac{1}{K_{s}}\right) P_{c}
$$

which is principally the same as the well-known Mackenzie equation modified to include saturation [44, 47, 48]. The product of capillary pressure and degree of saturation $S_{w}$ (i.e., $\left.S_{w} P_{c}\right)$ is named as the effective capillary stress $[44,47,48]$.

The above derivation actually takes little consideration of the characteristics of cementitious materials and is generally applicable to most elastic porous materials. As a matter of fact, the $S_{w}$ is basically an approximation of the Bishop parameter $\chi$ (representing the contact area between liquid and solid) in unsaturated poromechanics $[49,50]$, due to its ease and convenience of measurement. In other expressions of the Bishop parameter, $\chi$, it is typically expressed as a function of degree of saturation $\chi=\chi\left(S_{w}\right)$ as well [51].

3.1.2. Application of Capillary Pressure Theory to Cementitious Materials. A majority of researchers identify capillary pressure as the principle shrinkage mechanism at high $\mathrm{RH}$ (greater than $40 \%$ to $50 \%$ range), as menisci are established in that humidity range $[5,52,53]$. In addition, several capillary pressure theory-based prediction models provide a reasonable prediction of shrinkage that agrees well with laboratory results $[25,54,55]$. The changes of physical properties and structures of OPC dried at a specific RH have been characterized using various techniques (e.g., nitrogen sorption and dynamic water vapor isotherm) to deduce the underlying mechanisms $[36,56]$. The supporting evidence for the validity of capillary pressure theory is that the OPC specimens reach a minimum of nitrogen-BET specific surface area when dried at around $40 \%-50 \% \mathrm{RH}[28,57]$. The hydrostatic capillary pressure can pull adjacent solid walls closer and result in micropore closure, which decreases the nitrogen accessible regions [58-60]. In addition, shrinkage from $100 \%$ to $40 \% \sim 50 \% \mathrm{RH}$ is primarily responsible for the irreversible component due to microstructure alteration (rearrangement and redistribution of calcium-silicate-hydrate), while drying below $40 \% \mathrm{RH}$ is almost fully recoverable, probably due to a change in shrinkage driving force $[30,59]$.

The direct implementation of (7) significantly underestimates the shrinkage strain of OPC by a factor of about $2 \mathrm{x}$ to $3 \mathrm{x}$. The primarily reason for that is that (7) is only strictly applicable to elastic porous materials. However, the shrinkage response of OPC during the first drying process at $50 \% \sim 100 \% \mathrm{RH}$ is not completely elastic, as most of the deformation is irreversible upon rewetting [36]. Considering the inelasticity, some researchers attempted to modify (7) by assigning plastic or viscoelastic properties to skeleton materials $[53,55]$. Besides, although the once-dried OPC specimen behaves almost elastically during the second drying process [61], (7) still underestimates the magnitude of the shrinkage, which is probably due to miscalculated elastic modulus [61] and oversimplified pore solution properties (without correction for water activity) [62]. Additionally, other mechanisms (e.g., disjoining pressure) may work jointly with capillary pressure on shrinkage deformation at high $\mathrm{RH}$ [32].

3.1.3. Effects of $w / c$ Ratio on Drying Shrinkage of OPC. Based on Kelvin-Laplace equations, at a certain RH, the internal capillary pressure is constant. Therefore, the main difference for Portland cement mixtures with varying w/c originates mainly from the value of degree of saturation, $S_{w}$, assuming the stiffness of the materials is similar. In addition, an OPC mixture with lower w/c ratio is likely to have a relatively finer pore structure (see Figure 3(a)) and hence a higher ability to resist moisture loss. As a consequence, 
the moisture loss of low w/c should be lower than that for high w/c OPC at the same RH under equilibrium, which corresponds to a relatively higher degree of saturation. Not surprisingly, a higher degree of saturation for lower w/c OPC at a certain equilibrated $\mathrm{RH}$ has been verified experimentally [33]. It indicates that the equilibrated drying shrinkage of a low w/c system should be larger than that of a high $\mathrm{w} / \mathrm{c}$ ratio at the same drying conditions when stiffness is similar. Although one could argue that the stiffness of OPC for various w/c ratios is different, this parameter itself is insufficient in explaining the considerable difference in the measured magnitude of shrinkage strain.

Numerous experimental investigations have been performed regarding the drying shrinkage and moisture loss for OPC of various $\mathrm{w} / \mathrm{c}$ ratios $[3,15,33,54,63-65]$. The main result from previous laboratory studies is that, for a lower $\mathrm{w} / \mathrm{c}$ OPC, the drying shrinkage and moisture loss are smaller. It should be noted that the drying shrinkage mentioned here is the pure drying component of specimens without consideration of self-desiccation. It should also be noted that the drying shrinkage increases with time as evaporation continues, and the measured time-dependent shrinkage value varies with $\mathrm{RH}$ (evaporate rate) and specimen sizes. Therefore, within the thermodynamic framework, the drying kinetic effects must be eliminated and equilibrated shrinkage should be compared. Based on the measured equilibrated drying shrinkage in an environmental scanning electron microscope chamber using very thin specimens, the results show that the general tendency is analogous to that measured macroscopically (i.e., smaller drying shrinkage for lower w/c ratio) [64]. Therefore, it is reasonable to assume that this is a consensus among most experimental data.

The explanation regarding the shrinkage tendency of various w/c OPC provided by various researchers is rather vague. It was, for example, claimed to be attributed to the greater water loss, which induces higher drying shrinkage when w/c ratio increases [66]. If this explanation was valid, then associated dominating shrinkage should be the result of moisture loss, since high w/c OPC has coarser pore structure and larger porosity. However, this argument is contradictory to the capillary pressure theory as discussed in Section 3.1.1. This inconsistency between the theoretical analysis and experimental data can be explained by a couple of reasons. First, the viscoelastic response of OPC with various w/c ratios may dominate the overall drying shrinkage, which invalids elasticity theory on shrinkage prediction; as explicitly reported by Feldman and Sereda [36], the irreversible shrinkage is greater as the $\mathrm{w} / \mathrm{c}$ ratio is higher, which explains the larger shrinkage of high w/c OPC, although its predicted elastic shrinkage should be smaller based on a refined pore structure (see Figure 3(a)). Secondly, the degree of saturation $S_{w}$ (in (7)) may not be an accurate parameter representing the contact area (i.e., Bishop parameter $\chi$ in poromechanics). The adoption of degree of saturation $S_{w}$ assumes that all water is in capillary form, which ignores the presence of adsorbed water and some nanopores where menisci are unstable. For lower $\mathrm{w} / \mathrm{c}$ OPC with a relative finer pore structure, it is likely that a higher proportion of water is in the nanopores which does not contribute to the effective capillary force. It may partially account for a lower pure drying shrinkage for low w/c OPC, although the predicted shrinkage is underestimated. On the other hand, the elastic modulus, which is expected to evolve over time and varies depending on the moisture status and microstructure, may not be comprehensively characterized.

3.1.4. Kinetics of Shrinkage. In a sealed system, the magnitude and kinetics of shrinkage (i.e., autogenous shrinkage) is also dependent on the w/c ratio but theoretically irrespective of the sample size. It is universally reported that low w/c ratio can result in a higher autogenous shrinkage due to stronger self-desiccation, which increases capillary stress [15]. Autogenous shrinkage mainly occurs in the first few weeks after initial setting, during which the hydration continues and the properties of young C-S-H evolve over time (e.g., aging and drying) [67]. Therefore, the kinetics of autogenous shrinkage is mainly dependent on the kinetics of hydration (relating to a time-dependent evolution of interior $\mathrm{RH}$ in micropores), as well as the early-age properties (e.g., elastic modulus, viscosity, and stress relaxation) of materials.

For an unsealed system, when cementitious material is exposed to low $\mathrm{RH}$, the gradient in water vapor pressure between drying surface and ambient induces evaporation. The rate of evaporation is dependent on the temperature, properties of the pore solution, the gradient of vapor pressure, the rate of air flow, and the diffusion coefficient. Evaporation from the drying surface induces the flow of liquid and diffusion of vapor in the interior of cementitious materials $[43,68]$. As far as the liquid is continuous, the difference in capillary pressure between surface and interior drives the Darcy flow of pore solution [68]. The rate of Darcy flow is dependent on the permeability, degree of saturation, and properties of pore solution (e.g., surface tension and viscosity) [69, 70]. It was observed that a sharp drying front was noted in drying matured materials, while a uniform moisture profile was observed for fresh materials, due to the difference in permeability [71, 72]. In addition, the modification of the surface tension of the pore solution [73] (e.g., by introducing shrinkage-reducing admixture) also renders a sharp drying front, due to the Marangoni effect that causes pore solution to flow away from regions of low surface tension (i.e., the more concentrated SRA solution at the top drying surface) $[44,71$, 74]. As far as the rate of internal water movement falls below the rate of evaporation at drying surface (i.e., nonuniform distribution of moisture content), a gradient of pore pressure occurs in the bulk samples. Typically, the drying surface has a higher capillary pressure and tends to shrink more than the interior regions. When the higher shrinkage at drying surface is restrained by the relative lower shrinkage at interior, a tensile stress is formed at surface, which may induce microcracking. Therefore, the kinetics of pure drying shrinkage (i.e., hydration is terminated and C-S-H is mature) is dependent on the rate of evaporation, properties of pore solution, pore structure, and sample geometry.

When cementitious materials are exposed to drying conditions at early ages, the scenario is even more complicated. The concurrence of self-desiccation and drying may result in different kinetics and magnitude of overall shrinkage. In other words, the overall shrinkage may not 
be simply a sum of autogenous shrinkage and pure drying shrinkage. More specifically, early-age drying can interrupt the hydration process, modify the moisture distribution, and affect the development of C-S-H properties. Therefore, it is important to assess the time-dependent properties of young cementitious materials, as well as the influence of drying on the evolution of early-age properties.

3.1.5. Modification of Effective Capillary Stress in AlkaliActivated Slag. As mentioned in Section 1, AAS suffers from considerable shrinkage deformation and the reason behind its larger shrinkage has not been explained yet. As expressed by (7), the higher shrinkage of AAS at the same RH (i.e., same capillary stress) could be attributed to the higher degree of saturation and lower stiffness. In particular, two parameters would affect the degree of saturation in porous materials, that is, pore size distribution and pore solution properties (i.e., surface tension and ionic concentration modified parameter $\left.x_{w}\right)$. AAS tends to have a finer pore structure than OPC, as measured by mercury intrusion porosimetry $[6,75]$. However, the finer pore structure of AAS does not result in a stronger resistance to moisture evaporation [14], which is probably due to water being more loosely bound on the structure of calcium-alkali-alumina-silicate-hydrate in AAS [76].

On the other hand, it has been reported that AAS has high alkalinity and lower water activity than OPC due to the salt effects (i.e., Raoult's law) [77]. The addition of sodium hydroxide solution as an activator is reported to increase the surface tension of pore solution in OPC [21]. Thus, it is reasonable to deduce that the alkalinity and surface tension of AAS are relatively higher than those of OPC. Figure 4 shows the correlation between Kelvin radius and $\mathrm{RH}$ for selected ion concentrations, that is, various alkalinity, and surface tensions. It can be seen that at the same RH under thermodynamic equilibrium the Kelvin radius $r_{c}$ of AAS is substantially larger than that of OPC. Therefore, the sizes of pores that are emptied in pastes having a higher surface tension and lower water activity (e.g., AAS system) are larger as compared to pastes which contain solutions having a smaller surface tension and higher water activity (e.g., OPC system). Alternatively, this would suggest a slightly higher liquid saturation level in AAS pastes at equal conditions. However, this explanation tends to contradict with the experimental findings as well [14]. In addition, as shown in Figure 1(c), the kinetics of drying between AAS and OPC do not show as dramatic of a difference, which indicates that the evolution of effective capillary pressure between these two systems would be similar. Conclusively, the considerable shrinkage of AAS is not likely because of a higher effective capillary pressure.

Previous research indicates that sodium hydroxideactivated slag can have a relatively lower elastic modulus than that of OPC (although the difference is marginal), which may explain the higher shrinkage of sodium hydroxideactivated slag. However, for sodium silicate-activated slag, its elastic modulus is higher than OPC [14]. It may indicate that the shrinkage performance of AAS, especially at high $\mathrm{RH}$, exhibits an inelastic characteristic, which cannot be

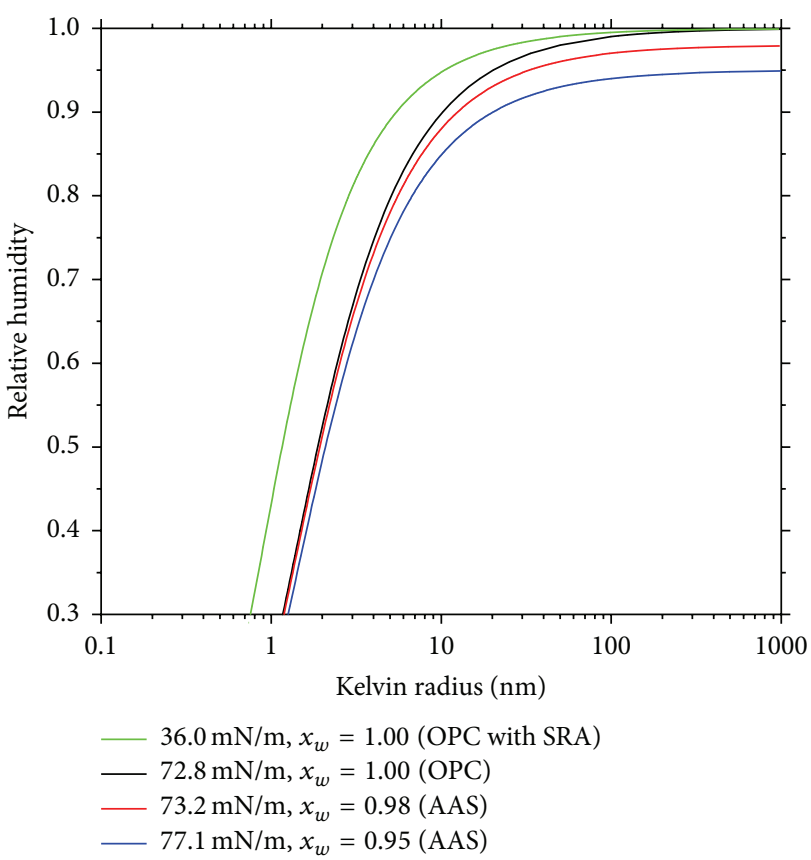

FIgURE 4: Correlation between Kelvin radius and $\mathrm{RH}$ for various cases of surface tensions and water activities. The values of liquid surface tension and water activity are postulated to represent AAS, plain OPC, and OPC with shrinkage-reducing admixture according to the research of $[21,22]$.

reasonably explained by elasticity theory. This characteristic will be elaborated in Section 3.2.3.

\subsection{Gibbs-Bangham Shrinkage}

3.2.1. Theoretical Basis of Gibbs-Bangham Shrinkage. As illustrated in Figure 5, the increased solid surface tension by desorption can induce compressive stress on the material's surface and render shrinkage (reversibly, absorption induces swelling). Since this type of stress has a close relation with the surface area, its influence can be significant for materials with high specific surface area, including cementitious materials.

From a thermodynamics point of view, there are several ways to derive the increase of surface energy due to water desorption $[23,34]$. The general form is based on the GibbsDuhem equation, following which one can obtain (8) as it is applied to the surface phases at isothermal condition [78]:

$$
-V d p+A d \gamma+N_{w} d \mu_{w}=0
$$

where $V=A l_{a}$ is volume $\left[\mathrm{m}^{3}\right], l_{a}$ is the thickness of adsorbed liquid [m], and $A$ is the surface area $\left[\mathrm{m}^{2}\right] ; N_{w}$ is the mass of water within the surface phase $[\mathrm{kg}] ; \mu_{w}$ is the chemical potential per unit mass $[\mathrm{J} / \mathrm{kg}] ; \gamma$ is surface tension $[\mathrm{N} / \mathrm{m}] ; p$ is the pressure in surface phase which in equilibrium equals the pressure in the vapor $[\mathrm{Pa}]$. Rewriting it further as a density form, one obtains

$$
-l_{a} d p+d \gamma+\Gamma_{w} d \mu_{w}=0
$$



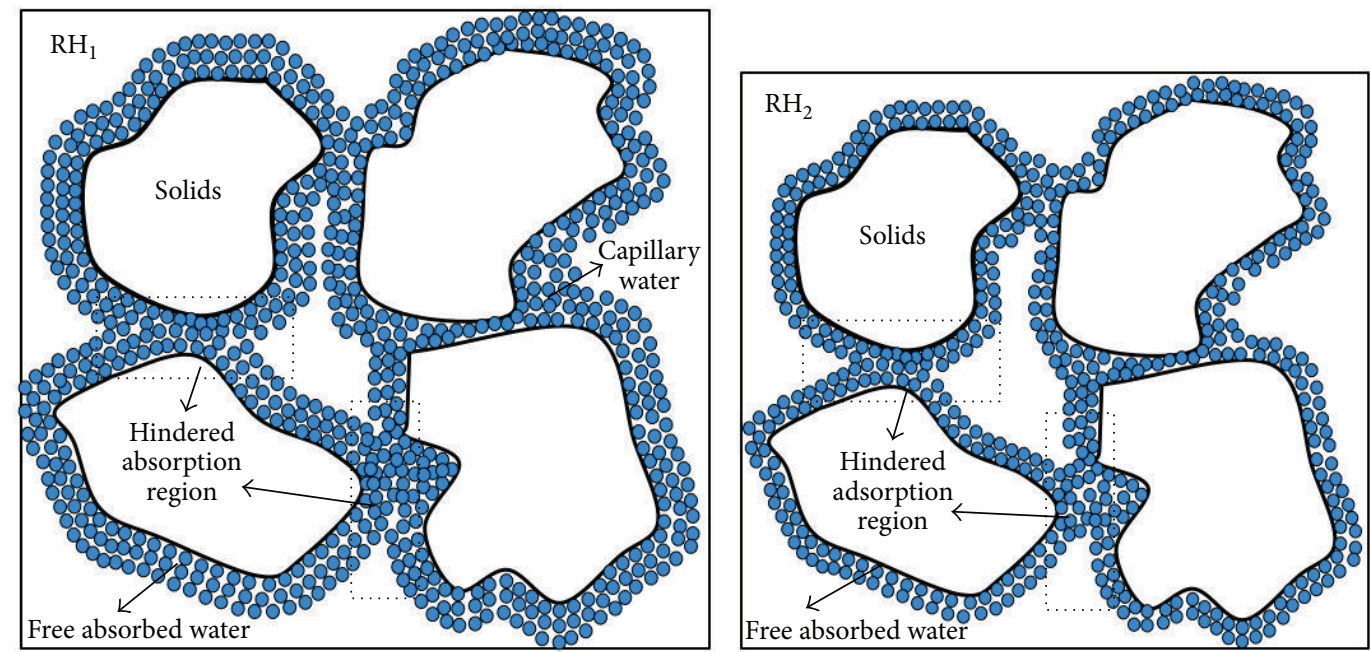

FIGURE 5: Schematic illustration of volumetric reduction due to change in surface free energy when desorption takes $\mathrm{place}\left(\mathrm{RH}_{2}<\mathrm{RH}_{1}\right)$.

where $\Gamma_{w}=N_{w} / A$ is the mass of surface phase per unit area or surface concentration $\left[\mathrm{kg} / \mathrm{m}^{2}\right]$. Since, under equilibrium conditions, the chemical potential of surface film $\mu_{w}$ is identical to the chemical potential $\mu_{v}$ of vapor in the atmosphere,

$$
d \mu_{w}=d \mu_{v}=R M^{-1} T d(\ln \mathrm{RH})
$$

where $M$ is molar mass of liquid $[\mathrm{kg} / \mathrm{mol}], R$ is the universal gas constant $[\mathrm{J} /(\mathrm{mol} \cdot \mathrm{K})]$, and $T$ is temperature $[\mathrm{K}]$. Thus, the isothermal change in surface tension can be expressed as

$$
\begin{aligned}
d \gamma & =-\Gamma_{w} R M^{-1} T d(\ln \mathrm{RH})+l_{a} d p \\
& \approx-\Gamma_{w} R M^{-1} T d(\ln \mathrm{RH}), \\
\Delta \gamma & =-R M^{-1} T \int_{\mathrm{RH}_{1}}^{\mathrm{RH}_{2}} \Gamma_{w} d(\ln \mathrm{RH}),
\end{aligned}
$$

where the surface concentration $\Gamma_{w}$ is a function of $\mathrm{RH}$.

Equation (12) indicates that the change of solid surface tension is primarily a function of $\mathrm{RH}$, irrespective of the structure and properties of materials. To correlate deformation, the classical Gibbs-Bangham equation is generally implemented [23]:

$$
\varepsilon_{\mathrm{GB}}=\Delta \gamma \cdot \lambda
$$

where $\varepsilon_{\mathrm{GB}}$ is the linear strain and $\lambda$ is a constant related to the material stiffness, specific mass, and pore wall surface $[\mathrm{m} / \mathrm{N}]$.

\subsubsection{Application of Gibbs-Bangham Equation to Cementi-} tious Materials. Gibbs-Bangham shrinkage has been considered by various researchers (e.g., Munich model [29] and DuCOM3 model [79]) as the dominant shrinkage mechanism for OPC, especially below $\sim 40 \% \mathrm{RH}$. Some researchers assumed that Gibbs-Bangham shrinkage is valid at high $\mathrm{RH}$ or even over a wide $\mathrm{RH}$ range [8]. The shift from capillary pressure theory to Gibbs-Bangham shrinkage at around
$40 \sim 50 \% \mathrm{RH}$ is primarily based on theoretical or experimental evidences: for instance, (1) the capillary meniscus that becomes unstable at $\sim 40 \% \mathrm{RH}$ (corresponding to the Kelvin radius of about $1 \mathrm{~nm}$ ) at which a drastic change in shrinkage mechanism would occur; (2) a noticeable change in the slope of shrinkage as a function of moisture loss at $\sim 40 \% \mathrm{RH}[80]$; (3) the shrinkage of materials dried directly below $\sim 40 \% \mathrm{RH}$ which is typically reversible after a sufficient rewetting time $[30,81]$; (4) the drying shrinkage that is somehow linearly proportional to the specific surface area [30]; (5) drying shrinkage that is strongly correlated to the moisture loss, regardless of drying $\mathrm{RH}$ and rates [8].

However, the calculated pure Gibbs-Bangham strain significantly underestimates the shrinkage, which is explained by Hansen to be the result of some additional accompanying types of shrinkage [8]. Similarly, Powers calculated the shrinkage due to change in surface tension and found that it accounts merely for a small fraction of the observed volumetric change [23]. According to (13), $\lambda$ is the important parameter that has not been exclusively investigated regarding its accuracy. In addition, although cementitious materials may behave elastically due to the surface energy-indicated compression, the influence of the dynamics of the desorption processes on Gibbs-Bangham shrinkage may also make a difference.

3.2.3. Correlation of Moisture Loss and Shrinkage. If GibbsBangham shrinkage was the dominant shrinkage mechanism in OPC with various w/c ratios, the drying shrinkage of low w/c OPC, for which moisture loss is lower, should be less than that of high w/c OPC. In addition, the drying shrinkage is strongly correlated with moisture loss for a certain w/c OPC, while it varies among different w/c cases. This tendency is consistent with experimental data [8].

In case of AAS, Gibbs-Bangham shrinkage only partially explains its shrinkage performance. As shown in Figure 1(a), the moisture loss and shrinkage strain of AAS is higher than that of OPC, which agrees with Gibbs-Bangham theory. 


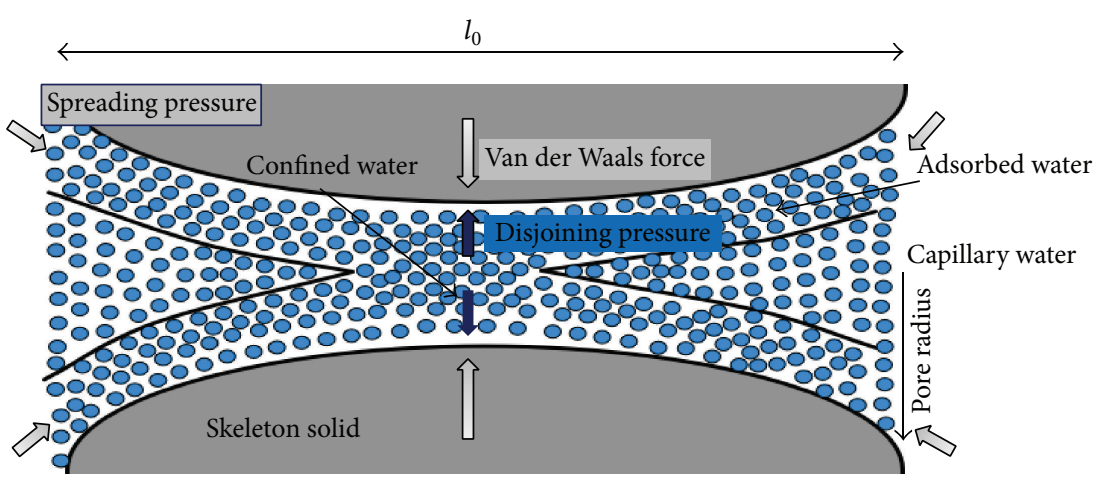

(a)

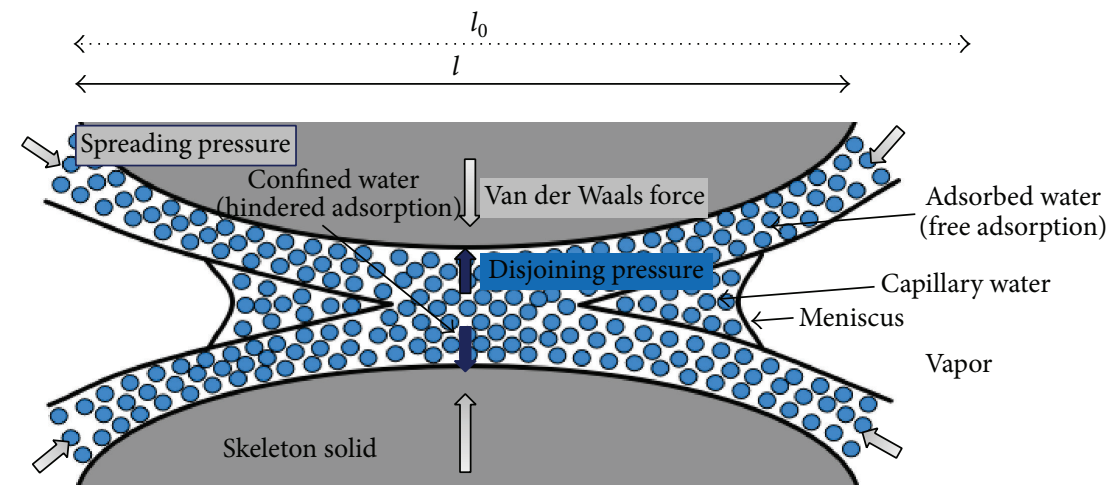

(b)

FIGURE 6: Schematic illustration of drying process in hindered adsorption region and withdrawal of disjoining pressure: (a) initial status, (b) after RH decreases. This figure shows the simultaneous occurrence of surface free energy-induced shrinkage and withdrawal of disjoining pressure-induced shrinkage.

However, it was reported that the drying rate affects notably the shrinkage behavior of AAS [12]. It means that the measured shrinkage strain can be drastically different under the same amount of moisture loss at various exposed RHs, which violates the Gibbs-Bangham shrinkage principles. Furthermore, it is important to notice that AAS shows significant time-dependent (viscous) shrinkage accumulation and can continue to shrink at a relatively high shrinkage rate during the drying process over a long-term period, even if little moisture loss is observed. Therefore, it is important to notice that the drying shrinkage of AAS is essentially associated with how the water moves through the system, rather than how much water is lost to external environments. Therefore, Gibbs-Bangham shrinkage is not the main mechanism responsible for the large magnitude of shrinkage in AAS.

\subsection{Disjoining Pressure}

3.3.1. Theoretical Basis of Disjoining Pressure. As illustrated in Figure 6, at initial stage, the preexistence of disjoining pressure in nanopores is balanced by the spreading pressure (see Figure 6), exerting longitudinally to the interspace between different solid skeleton surfaces. As RH decreases and water evaporates, the preexerting force decreases, releasing disjoining pressure, as well as reducing the distance between these two surfaces (i.e., shrinkage). The withdrawal of disjoining pressure is inevitably related to desorption of water molecules and increase in solid surface free energy. In addition, the capillary meniscus, if present adjacent to the nanopores, can also affect the disjoining pressure [82].

According to the force balance in the direction parallel to the skeleton surface, the change in spreading pressure $d \pi$ can be expressed as [78]

$$
d \pi=-d \gamma=\Gamma_{w} R M^{-1} T d(\ln \mathrm{RH}) .
$$

Thus, the change in averaged longitudinally normal pressure withdrawn is [34]

$$
\begin{aligned}
\Delta p_{\pi} & =\int_{\mathrm{RH}_{0}}^{\mathrm{RH}} \frac{d \pi}{l_{a}}=R M^{-1} T \int_{\mathrm{RH}_{0}}^{\mathrm{RH}} \frac{\Gamma_{w}\left(l_{a}\right)}{l_{a}} d(\ln \mathrm{RH}) \\
& =\rho_{w} R M^{-1} T \ln \left(\frac{\mathrm{RH}}{\mathrm{RH}_{0}}\right), \quad \mathrm{RH} \geq \mathrm{RH}_{f}(r),
\end{aligned}
$$

where $\mathrm{RH}_{f}$ is the critical $\mathrm{RH}$ at which a certain thickness of pore becomes filled at constant temperature. It should be noted that $p_{\pi}$ substantially differs from disjoining pressure $p_{\Pi}$, both in direction and in magnitude. It can also be seen that the value of $\mathrm{RH}_{f}$ varies for different pore sizes under isothermal condition and tends to be smaller for finer pores. The disjoining pressure in a certain size of pore is completely released when the $\mathrm{RH}$ is below $\mathrm{RH}_{f}$. However, 

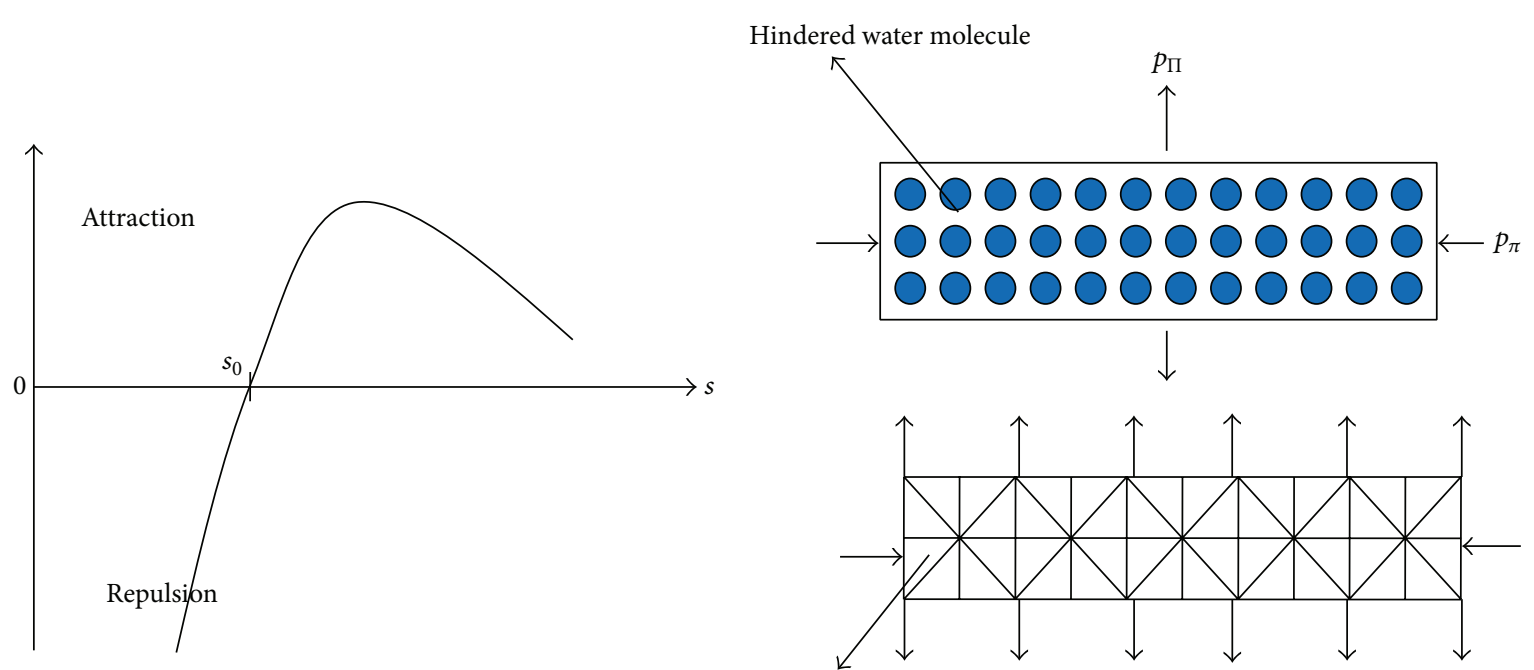

One idealized truss model for water molecule arrangement

(a)

(b)

FIGURE 7: (a) Interatomic force in each individual water molecule; (b) an idealized water molecule arragement model for correlating disjoining pressure and spreading pressure.

when $\mathrm{RH}$ in the macropore is raised above the value $\mathrm{RH}_{f}$ under thermodynamic equilibrium, the $\Gamma_{w}$ in a filled pore of constant thickness is almost constant. In addition, the value of preexisted disjoining pressure is larger for pores with a smaller diameter at the same $\mathrm{RH}$.

As idealized in Figure 7, if one assumes that the hindered adsorption water molecules behave analogically to isotropic elastic solids, the following can be obtained [83]:

$$
d p_{\Pi}=k \cdot d p_{\pi},
$$

where $k=\partial p_{\Pi} / \partial p_{\pi}$ is a disjoining ratio, analogous to the Poisson ratio of elastic solids $[\mathrm{Pa} / \mathrm{Pa}]$. By definition, the value of disjoining ratio represents the sensitivity of disjoining pressure in terms of normal pressure and RH. Figure 7(b) shows a potential model to calculate the value of $k$ by idealizing the water molecules arrangement in the hindered adsorption region [83]. It is implicit that the value of $k$ varies with pore size and $\mathrm{RH}$. The quantitative determination of the value of $k$ or its mathematical expression is difficult to obtain without considering its molecules arrangement in hindered pores. It is also important to note that the water can only be present in hindered condition when the thickness of the pore is below several nanometers.

3.3.2. Application of Disjoining Pressure Theory to Cementitious Materials. The application of disjoining pressure theory to shrinkage of cementitious material remains controversial. While some researchers considered it to be important $[32,34]$ others rejected it [36]. In addition, some assume it dominates at high RH (e.g., above 40\% RH in Munich model [29]), while others assume it works over a wide range of $\mathrm{RH}$ [23]. Meanwhile, other models assume it to be valid at low RH (e.g., DuCOM3 model [79]).

Disjoining pressure is generated by the confined water in the narrow spaces (sometimes defined as pores $<2.6 \mathrm{~nm}$ wide, i.e., 10 molecules wide [83]) as a form of hindered adsorption layer and acts as the repulsive force toward solid particles. Accordingly, the distance between solid particles decreases when the repulsive force decreases. An essential point concerning disjoining pressure is whether the classical macroscopic Young-Laplace equation is valid for fine pores, since the solid-liquid interfacial tension and the configuration of confined water molecules may be different from that found in large pores [84]. In addition, the larger proportion of physically adsorbed water also affects the capillary tension in fine pores. As pointed out by Farrer and Fourkas, water confined in nanospace is discontinuous with only tens of molecules [85]. If water molecules move discretely and closely to particles, the withdrawn disjoining pressure changes drastically and as a result generates shrinkage. One open question related to the initial magnitude of preexisting disjoining pressure and the relation between the change in disjoining pressure and the reduced $\mathrm{RH}$ still exists. Considering that for cementitious materials there is a large proportion of water in nanopores, disjoining forces are very likely to play a major role. However, a reasonable quantification of disjoining pressure and its application to predicting shrinkage of cementitious materials are still lacking. The emerging molecular dynamic simulation techniques may shed some light on the mechanisms of disjoining pressure in C-S-H [86].

If one assumes that the majority of the pores in OPC are in the range where disjoining pressure works and the magnification of $k$ is similar for each size of pore, the released disjoining pressure is likely to be less for low w/c OPC since it loses relatively less moisture. As mentioned before, the disjoining pressure is active merely in fine pores and the released pressure is associated with the pore diameter; therefore the disjoining pressure is unable to comprehensively explain the shrinkage tendency in OPC without a more rigid molecular modeling. 
Disjoining pressure, however, may partially explain the shrinkage behavior of AAS. Since AAS has a finer pore structure, the proportion of pores in the range of disjoining pressure-active range may be higher. Also, according to the experimental results (see Figure 1(a)) showing that the moisture loss of AAS is larger than that of OPC, the withdrawn disjoining pressure is, correspondingly, larger than that of OPC. On the other hand, the release of disjoining pressure in hindered adsorption region shows notably time-dependent properties (associated with internal water movement and redistribution [87]), which agrees with timedependent shrinkage behavior of AAS (see Figure 1(b)). However, this speculation needs further investigation.

\section{Concluding Remarks}

In this paper, the main existing shrinkage mechanisms and relevant prediction models for cementitious materials are briefly reviewed. In addition, a comparative study is performed between OPC with two w/c ratios and AAS. It indicates that the shrinkage mechanisms for OPC and AAS vary significantly, which is likely to be associated with differences in pore structure and inelasticity (e.g., viscoelastic and viscoplastic of mechanical properties). It is appealing to investigate the time-dependent evolution of the microstructure of various cementitious systems upon dryinginduced stress. This review underlines the importance of examining the liquid status (e.g., capillary-condensed water and adsorbed film) of pore solution in paste, which is the core of understanding the dominant interaction mechanisms between liquid and solid skeleton. Additionally, since some researchers favor to explain the shrinkage performance of cement-based systems by a result of various shrinkage mechanisms working at various sizes of pores, it is important to name the critical pore size or critical $\mathrm{RH}$, which defines the boundary between the operating regions of different dominant shrinkage mechanisms.

\section{Competing Interests}

The authors declare that they have no competing interests.

\section{Acknowledgments}

The authors gratefully acknowledge the financial support from the U.S. National Science Foundation (NSF) under Award CMMI no. 1265789. Any opinions, findings, and conclusions or recommendations expressed in this material are those of the authors and do not necessarily reflect the views of the NSF.

\section{References}

[1] A. M. Neville, Properties of Concrete, Pitman Publishing, New York, NY, USA, 1981.

[2] E.-I. Tazawa, Autogenous Shrinkage of Concrete, CRC Press, Philadelphia, Pa, USA, 2003.
[3] E.-I. Tazawa and S. Miyazawa, "Experimental study on mechanism of autogenous shrinkage of concrete," Cement and Concrete Research, vol. 25, no. 8, pp. 1633-1638, 1995.

[4] D. P. Bentz, "A review of early-age properties of cement-based materials," Cement and Concrete Research, vol. 38, no. 2, pp. 196204, 2008.

[5] K. Kovler and S. Zhutovsky, "Overview and future trends of shrinkage research," Materials and Structures, vol. 39, no. 293, pp. 827-847, 2006.

[6] F. Collins and J. G. Sanjayan, "Effect of pore size distribution on drying shrinking of alkali-activated slag concrete," Cement and Concrete Research, vol. 30, no. 9, pp. 1401-1406, 2000.

[7] C. F. Ferraris and F. H. Wittmann, "Shrinkage mechanisms of hardened cement paste," Cement and Concrete Research, vol. 17, no. 3, pp. 453-464, 1987.

[8] W. Hansen, "Drying shrinkage mechanisms in Portland cement paste," Journal of the American Ceramic Society, vol. 70, no. 5, pp. 323-328, 1987.

[9] D. P. Bentz and M. A. Peltz, "Reducing thermal and autogenous shrinkage contributions to early-age cracking," ACI Materials Journal, vol. 105, no. 4, pp. 414-420, 2008.

[10] Y. Akkaya, C. Ouyang, and S. P. Shah, "Effect of supplementary cementitious materials on shrinkage and crack development in concrete," Cement and Concrete Composites, vol. 29, no. 2, pp. 117-123, 2007.

[11] N. K. Lee, J. G. Jang, and H. K. Lee, "Shrinkage characteristics of alkali-activated fly ash/slag paste and mortar at early ages," Cement and Concrete Composites, vol. 53, pp. 239-248, 2014.

[12] H. Ye, C. Cartwright, F. Rajabipour, and A. Radlińska, "Effect of drying rate on shrinkage of alkali-activated slag cements," in Proceedings of the 4th International Conference on the Durability of Concrete Structure (ICDCS '14), pp. 254-261, Purdue University, July 2014.

[13] C. Cartwright, F. Rajabipour, and A. Radlińska, "Shrinkage characteristics of alkali-activated slag cements," in Proceedings of the 3rd International Conference on Sustainable Construction Materials and Technology (SCMT '13), Kyoto, Japan, August 2013.

[14] C. Cartwright, F. Rajabipour, and A. Radlińska, "Shrinkage characteristics of alkali-activated slag cements," ASCE Journal of Materials in Civil Engineering, vol. 27, no. 7, Article ID B4014007, 2015.

[15] V. Baroghel-Bouny, P. Mounanga, A. Khelidj, A. Loukili, and N. Rafaï, "Autogenous deformations of cement pastes. Part II. W/C effects, micro-macro correlations, and threshold values," Cement and Concrete Research, vol. 36, no. 1, pp. 123-136, 2006.

[16] Y. Ma and G. Ye, "The shrinkage of alkali activated fly ash," Cement and Concrete Research, vol. 68, pp. 75-82, 2015.

[17] A. R. Sakulich and D. P. Bentz, "Mitigation of autogenous shrinkage in alkali activated slag mortars by internal curing," Materials and Structures, vol. 46, no. 8, pp. 1355-1367, 2013.

[18] M. Jiang, X. Chen, F. Rajabipour, and C. T. Hendrickson, "Comparative life cycle assessment of conventional, glass powder, and alkali-activated slag concrete and mortar," Journal of Infrastructure Systems, vol. 20, no. 4, 2014.

[19] C. Shi, P. V. Krivenko, and D. Roy, Alkali-Activated Cements and Concretes, Taylor \& Francis, 2005

[20] F. Collins and J. G. Sanjayan, "Microcracking and strength development of alkali activated slag concrete," Cement and Concrete Composites, vol. 23, no. 4-5, pp. 345-352, 2001. 
[21] G. Sant, A. Kumar, C. Patapy, G. Le Saout, and K. Scrivener, "The influence of sodium and potassium hydroxide on volume changes in cementitious materials," Cement and Concrete Research, vol. 42, no. 11, pp. 1447-1455, 2012.

[22] A. Radlinska, F. Rajabipour, B. Bucher, R. Henkensiefken, G. Sant, and J. Weiss, "Shrinkage mitigation strategies in cementitious systems: a closer look at differences in sealed and unsealed behavior," Transportation Research Record, vol. 2070, pp. 59-67, 2008.

[23] T. C. Powers, "The thermodynamics of volume change and creep," Matériaux et Constructions, vol. 1, no. 6, pp. 487-507, 1968.

[24] J. R. Thompson, Empirical Model Building: Data, Models, and Reality, John Wiley \& Sons, 2011.

[25] O. Coussy, R. Eymard, and T. Lassabatère, "Constitutive modeling of unsaturated drying deformable materials," Journal of Engineering Mechanics, vol. 124, no. 6, pp. 658-667, 1998.

[26] O. Coussy, P. Dangla, T. Lassabatère, and V. Baroghel-Bouny, "The equivalent pore pressure and the swelling and shrinkage of cement-based materials," Materials and Structures, vol. 37, no. 265, pp. 15-20, 2004.

[27] D. Gawin, F. Pesavento, and B. A. Schrefler, "Hygro-thermochemo-mechanical modelling of concrete at early ages and beyond. Part II. Shrinkage and creep of concrete," International Journal for Numerical Methods in Engineering, vol. 67, no. 3, pp. 332-363, 2006.

[28] I. Maruyama, Y. Nishioka, G. Igarashi, and K. Matsui, "Microstructural and bulk property changes in hardened cement paste during the first drying process," Cement and Concrete Research, vol. 58, pp. 20-34, 2014.

[29] F. H. Wittmann, "Interaction of hardened cement paste and water," Journal of the American Ceramic Society, vol. 56, no. 8, pp. 409-415, 1973.

[30] I. Maruyama, G. Igarashi, and Y. Nishioka, "Bimodal behavior of C-S-H interpreted from short-term length change and water vapor sorption isotherms of hardened cement paste," Cement and Concrete Research, vol. 73, pp. 158-168, 2015.

[31] F. Wittmann, "Heresies on shrinkage and creep mechanisms," in Proceedings of the 8th International Conference on Creep, Shrinkage and Durability Mechanics of Concrete and Concrete Structures (CONCREEP8 '08), pp. 3-9, September 2008.

[32] F. Beltzung and F. H. Wittmann, "Role of disjoining pressure in cement based materials," Cement and Concrete Research, vol. 35, no. 12, pp. 2364-2370, 2005.

[33] I. Maruyama, "Origin of drying shrinkage of hardened cement paste: hydration pressure," Journal of Advanced Concrete Technology, vol. 8, no. 2, pp. 187-200, 2010.

[34] Z. P. Bažant, "Thermodynamics of interacting continua with surfaces and creep analysis of concrete structures," Nuclear Engineering and Design, vol. 20, no. 2, pp. 477-505, 1972.

[35] Z. P. Bažant, "Prediction of concrete creep and shrinkage: past, present and future," Nuclear Engineering and Design, vol. 203, no. 1, pp. 27-38, 2001.

[36] R. F. Feldman and P. J. Sereda, "A model for hydrated Portland cement paste as deduced from sorption-length change and mechanical properties," Matériaux et Construction, vol. 1, no. 6, pp. 509-520, 1968.

[37] W. A. Gutteridge and L. J. Parrott, "A study of the changes in weight, length and interplanar spacing induced by drying and rewetting synthetic CSH (I)," Cement and Concrete Research, vol. 6 , no. 3, pp. 357-366, 1976.
[38] P. Lura, O. M. Jensen, and K. van Breugel, "Autogenous shrinkage in high-performance cement paste: an evaluation of basic mechanisms," Cement and Concrete Research, vol. 33, no. 2, pp. 223-232, 2003.

[39] T. Young, "An essay on the cohesion of fluids," Philosophical Transactions of the Royal Society of London, vol. 95, pp. 65-87, 1805.

[40] H.-J. Butt, K. Graf, and M. Kappl, Physics and Chemistry of Interfaces, John Wiley \& Sons, New York, NY, USA, 2006.

[41] R. Badmann, N. Stockhausen, and M. J. Setzer, "The statistical thickness and the chemical potential of adsorbed water films," Journal of Colloid and Interface Science, vol. 82, no. 2, pp. 534$542,1981$.

[42] A. W. Adamson and A. P. Gast, Physical Chemistry of Surfaces, Interscience Publishers, 1967.

[43] G. W. Scherer, "Theory of drying," Journal of the American Ceramic Society, vol. 73, no. 1, pp. 3-14, 1990.

[44] D. P. Bentz, "Curing with shrinkage-reducing admixtures," Concrete International. Detroit, vol. 27, p. 55, 2005.

[45] V. Baroghel-Bouny, "Water vapour sorption experiments on hardened cementitious materials: part I: essential tool for analysis of hygral behaviour and its relation to pore structure," Cement and Concrete Research, vol. 37, no. 3, pp. 414-437, 2007.

[46] P. Schiller, T. Bier, M. Wahab, and H.-J. Mögel, "Mesoscopic model of volume changes due to moisture variations in porous materials," Colloids and Surfaces A: Physicochemical and Engineering Aspects, vol. 327, no. 1-3, pp. 34-43, 2008.

[47] D. P. Bentz, E. J. Garboczi, and D. A. Quenard, "Modelling drying shrinkage in reconstructed porous materials: application to porous Vycor glass," Modelling and Simulation in Materials Science and Engineering, vol. 6, no. 3, pp. 211-236, 1998.

[48] J. Mackenzie, "The elastic constants of a solid containing spherical holes," Proceedings of the Physical Society Section B, vol. 63, no. 1, pp. 2-11, 1950.

[49] B. A. Schrefler, L. Simoni, L. Xikui, and O. C. Zienkiewicz, "Mechanics of partially saturated porous media," in Numerical Methods and Constitutive Modelling in Geomechanics, vol. 311 of International Centre for Mechanical Sciences, pp. 169-209, Springer, Vienna, Austria, 1990.

[50] B. A. Schrefler, "Mechanics and thermodynamics of saturated/unsaturated porous materials and quantitative solutions," Applied Mechanics Reviews, vol. 55, no. 4, pp. 351-388, 2002.

[51] A. W. Skempton, "Effective stress in soils, concrete and rocks," in Selected Papers on Soil Mechanics, pp. 106-118, Thomas Telford Publishing, London, UK, 1984.

[52] C. Hua, A. Ehrlacher, and P. Acker, "Analyses and models of the autogenous shrinkage of hardening cement paste II. Modelling at scale of hydrating grains," Cement and Concrete Research, vol. 27, no. 2, pp. 245-258, 1997.

[53] C. Hua, P. Acker, and A. Ehrlacher, "Analyses and models of the autogenous shrinkage of hardening cement paste. I. Modelling at macroscopic scale," Cement and Concrete Research, vol. 25, no. 7, pp. 1457-1468, 1995.

[54] J. Zhang, D. Hou, and Y. Han, "Micromechanical modeling on autogenous and drying shrinkages of concrete," Construction and Building Materials, vol. 29, pp. 230-240, 2012.

[55] Z. C. Grasley and C. K. Leung, "Desiccation shrinkage of cementitious materials as an aging, poroviscoelastic response," Cement and Concrete Research, vol. 41, no. 1, pp. 77-89, 2011.

[56] F. Wittmann, "The structure of hardened cement paste-a basis for a better understanding of the materials properties," in 
Hydraulic Cement Pastes: Their Structure and Properties, pp. 96117, Cement and Concrete Association, Slough, UK, 1976.

[57] L. J. Parrott, W. Hansen, and R. L. Berger, "Effect of first drying upon the pore structure of hydrated alite paste," Cement and Concrete Research, vol. 10, no. 5, pp. 647-655, 1980.

[58] H. M. Jennings, "A model for the microstructure of calcium silicate hydrate in cement paste," Cement and Concrete Research, vol. 30, no. 1, pp. 101-116, 2000.

[59] H. M. Jennings, "Refinements to colloid model of C-S-H in cement: CM-II," Cement and Concrete Research, vol. 38, no. 3, pp. 275-289, 2008.

[60] J. J. Thomas and H. M. Jennings, "A colloidal interpretation of chemical aging of the $\mathrm{C}-\mathrm{S}-\mathrm{H}$ gel and its effects on the properties of cement paste," Cement and Concrete Research, vol. 36, no. 1, pp. 30-38, 2006.

[61] I. Vlahinić, H. M. Jennings, and J. J. Thomas, "A constitutive model for drying of a partially saturated porous material," Mechanics of Materials, vol. 41, no. 3, pp. 319-328, 2009.

[62] H. Chen, M. Wyrzykowski, K. Scrivener, and P. Lura, "Prediction of self-desiccation in low water-to-cement ratio pastes based on pore structure evolution," Cement and Concrete Research, vol. 49, pp. 38-47, 2013.

[63] Y. Yang, R. Sato, and K. Kawai, "Autogenous shrinkage of highstrength concrete containing silica fume under drying at early ages," Cement and Concrete Research, vol. 35, no. 3, pp. 449-456, 2005.

[64] C. M. Neubauer, T. B. Bergstrom, K. Sujata, Y. Xi, E. J. Garboczi, and H. M. Jennings, "Drying shrinkage of cement paste as measured in an environmental scanning electron microscope and comparison with microstructural models," Journal of Materials Science, vol. 32, no. 24, pp. 6415-6427, 1997.

[65] I. Yurtdas, H. Peng, N. Burlion, and F. Skoczylas, "Influences of water by cement ratio on mechanical properties of mortars submitted to drying," Cement and Concrete Research, vol. 36, no. 7, pp. 1286-1293, 2006.

[66] M. H. Zhang, C. T. Tam, and M. P. Leow, "Effect of water-tocementitious materials ratio and silica fume on the autogenous shrinkage of concrete," Cement and Concrete Research, vol. 33, no. 10, pp. 1687-1694, 2003.

[67] D. P. Bentz and O. M. Jensen, "Mitigation strategies for autogenous shrinkage cracking," Cement and Concrete Composites, vol. 26, no. 6, pp. 677-685, 2004.

[68] G. W. Scherer, "Drying, shrinkage, and cracking of cementitious materials," Transport in Porous Media, vol. 110, no. 2, pp. 311-331, 2015.

[69] O. Coussy, Poromechanics, John Wiley \& Sons, Chichester, UK, 2004.

[70] M. T. van Genuchten, "A closed-form equation for predicting the hydraulic conductivity of unsaturated soils," Soil Science Society of America Journal, vol. 44, no. 5, pp. 892-898, 1980.

[71] D. P. Bentz, M. R. Geiker, and K. K. Hansen, "Shrinkagereducing admixtures and early-age desiccation in cement pastes and mortars," Cement and Concrete Research, vol. 31, no. 7, pp. 1075-1085, 2001.

[72] V. Baroghel-Bouny, M. Mainguy, T. Lassabatere, and O. Coussy, "Characterization and identification of equilibrium and transfer moisture properties for ordinary and high-performance cementitious materials," Cement and Concrete Research, vol. 29, no. 8, pp. 1225-1238, 1999.

[73] F. Rajabipour, G. Sant, and J. Weiss, "Interactions between shrinkage reducing admixtures (SRA) and cement paste's pore solution," Cement and Concrete Research, vol. 38, no. 5, pp. 606$615,2008$.

[74] D. P. Bentz, "Influence of shrinkage-reducing admixtures on early-age properties of cement pastes," Journal of Advanced Concrete Technology, vol. 4, no. 3, pp. 423-429, 2006.

[75] A. A. M. Neto, M. A. Cincotto, and W. Repette, "Mechanical properties, drying and autogenous shrinkage of blast furnace slag activated with hydrated lime and gypsum," Cement and Concrete Composites, vol. 32, no. 4, pp. 312-318, 2010.

[76] M. Guerrieri and J. Sanjayan, "Investigation of the cause of disintegration of alkali-activated slag at temperature exposure of $50^{\circ} \mathrm{C}$," Journal of Materials in Civil Engineering, vol. 23, no. 12, pp. 1589-1595, 2011.

[77] S. Song and H. M. Jennings, "Pore solution chemistry of alkaliactivated ground granulated blast-furnace slag," Cement and Concrete Research, vol. 29, no. 2, pp. 159-170, 1999.

[78] Z. P. Bažant, "Mathematical model for creep and thermal shrinkage of concrete at high temperature," Nuclear Engineering and Design, vol. 76, no. 2, pp. 183-191, 1983.

[79] K. Maekawa, T. Ishida, and T. Kishi, "Multi-scale modeling of concrete performance," Journal of Advanced Concrete Technology, vol. 1, no. 2, pp. 91-126, 2003.

[80] S. Mindess, J. F. Young, and D. Darwin, Concrete, Prentice-Hall, Upper Saddle River, NJ, USA, 2003.

[81] R. F. Feldman, Sorption and Length-Change Scanning Isotherms of Methanol and Water on Hydrated Portland Cement, National Research Council of Canada, Ottawa, Canada, 1970.

[82] A. V. Neimark, P. I. Ravikovitch, and A. Vishnyakov, "Bridging scales from molecular simulations to classical thermodynamics: density functional theory of capillary condensation in nanopores," Journal of Physics: Condensed Matter, vol. 15, no. 3, pp. 347-365, 2003.

[83] Z. P. Bazant and M. Z. Bazant, "Theory of sorption hysteresis in nanoporous solids: part I: snap-through instabilities," Journal of the Mechanics and Physics of Solids, vol. 60, no. 9, pp. 1644-1659, 2012.

[84] Y. Qiao, L. Liu, and X. Chen, "Pressurized liquid in nanopores: a modified Laplace-Young equation," Nano Letters, vol. 9, no. 3, pp. 984-988, 2009.

[85] R. A. Farrer and J. T. Fourkas, "Orientational dynamics of liquids confined in nanoporous sol-gel glasses studied by optical Kerr effect spectroscopy," Accounts of Chemical Research, vol. 36, no. 8, pp. 605-612, 2003.

[86] P. A. Bonnaud, Q. Ji, B. Coasne, R. J.-M. Pellenq, and K. J. Van Vliet, "Thermodynamics of water confined in porous calciumsilicate-hydrates," Langmuir, vol. 28, no. 31, pp. 11422-11432, 2012.

[87] H. Ye, "Creep mechanisms of calcium-silicate-hydrate: an overview of recent advances and challenges," International Journal of Concrete Structures and Materials, vol. 9, no. 4, pp. 453-462, 2015. 

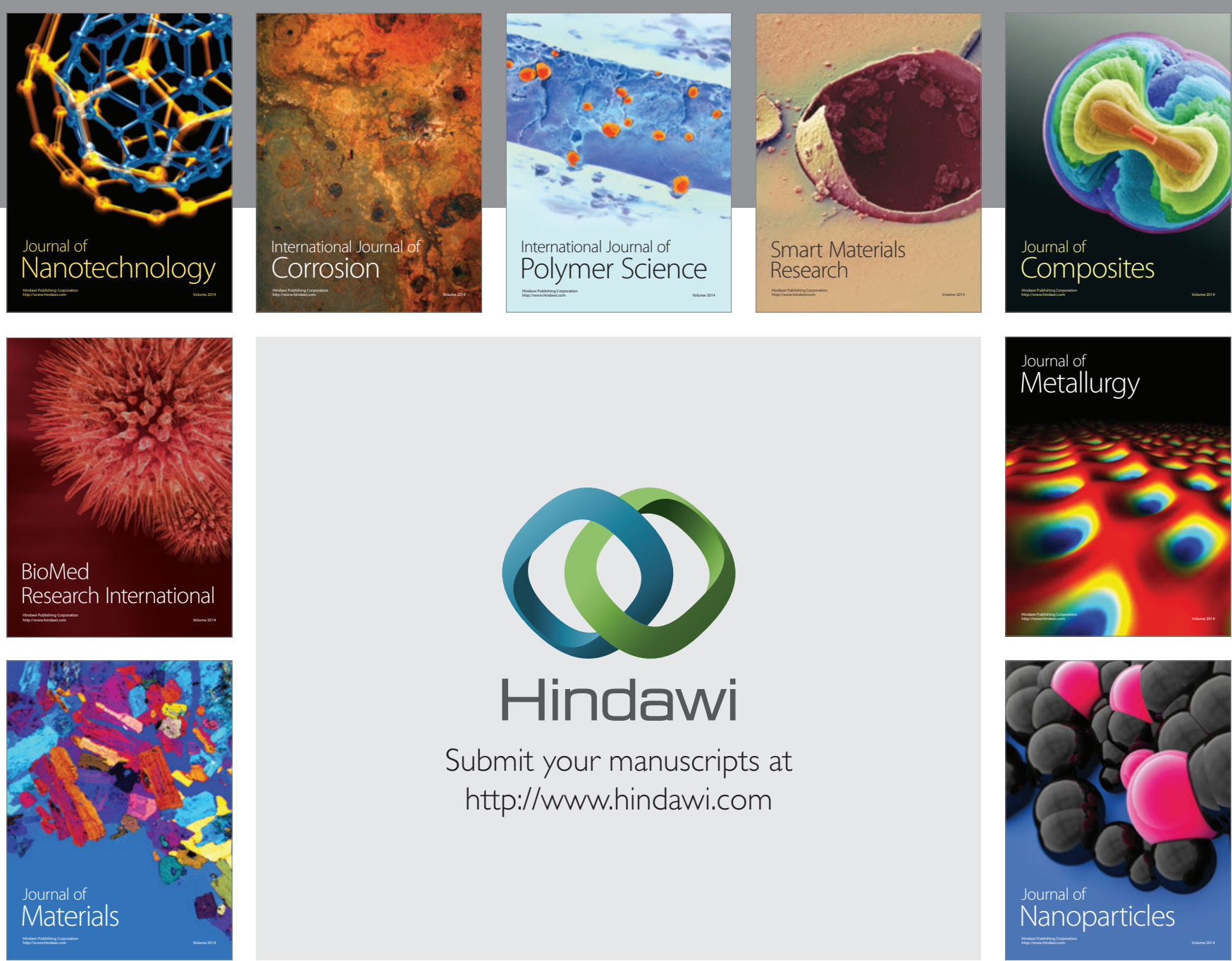

\section{Hindawi}

Submit your manuscripts at

http://www.hindawi.com

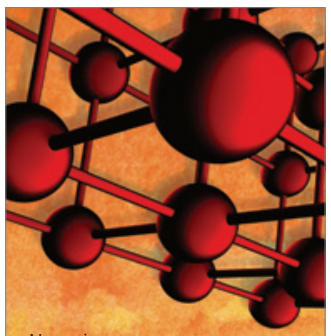

Materials Science and Engineering
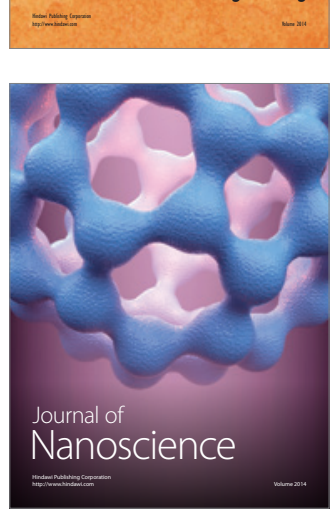
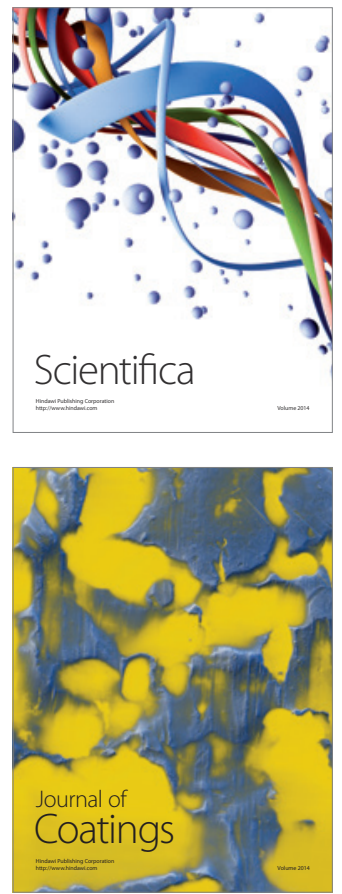
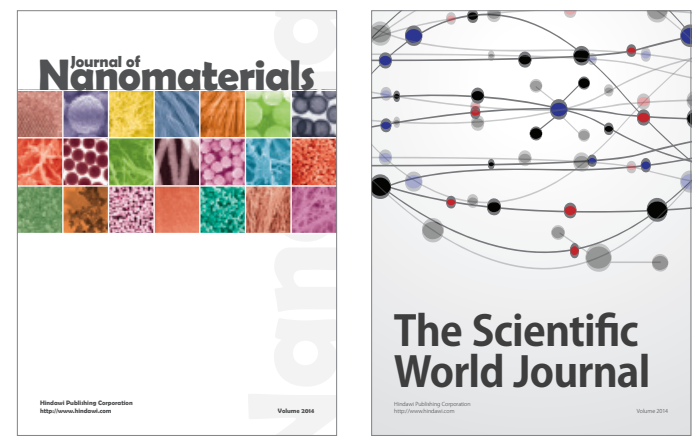

The Scientific World Journal
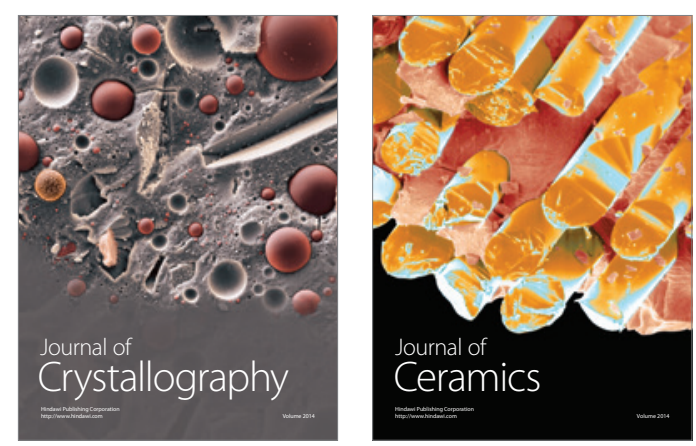
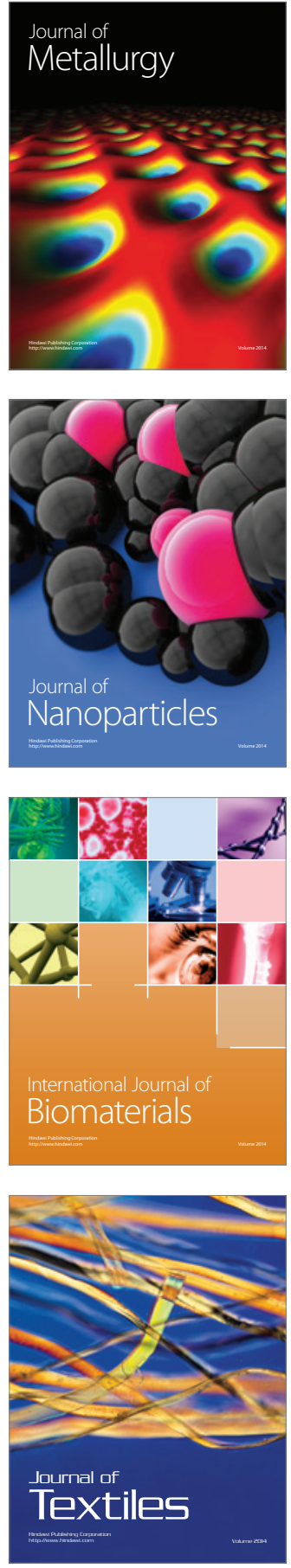